\title{
Relatedness and diversification in the European Union (EU-27) and European Neighbourhood Policy countries
}

\author{
Ron Boschma \\ CIRCLE, Lund University, Sweden and URU, Utrecht University, P.O. Box 80.115, 3508 \\ TC Utrecht, The Netherlands; e-mail: r.boschma@geo.uu.nl, ron.boschma@circle.lu.se \\ Gianluca Capone \\ Institute for Advanced Studies (IUSS), Piazza della Vittoria 15, 27100 Pavia, Italy; \\ e-mail: gianluca.capone@iusspavia.it \\ Received 11 February 2014; in revised form 23 December 2014; published online \\ 9 December 2015
}

\begin{abstract}
This paper analyzes the process of industrial diversification in the countries that were part of the European Union (EU-27) and those that were the target of the European Neighbourhood Policy (ENP) in the period 1995-2010 by means of world trade data derived from the BACI database (elaborated UN Comtrade data). Our results show that in both the EU-27 and the ENP countries, the evolution of the productive structure-as proxied by the export mix -is strongly path-dependent: countries tend to keep a comparative advantage in products that are strongly related to their current productive structure, and they also diversify in nearby products. However, this effect is much stronger for ENP countries, signalling their lower resources and capabilities to diversify in products that are not very related to their productive structure. We also show that the future export structures of countries are affected by their imports: both the EU-27 and ENP countries keep a comparative advantage in products that are strongly related to their imports, but only EU countries show a strong capability to diversify in new products from related import sectors. Our results also hold when controlling for geographical and institutional proximity.
\end{abstract}

Keywords: Diversification, relatedness, European Neighborhood Policy, trade

\section{Introduction}

The evolution of the productive structure of countries is a relevant topic from both an academic and a policy point of a view. There is a strong heterogeneity in what countries produce, that has important implications for their economic development and wealth. The traditional paradigm of trade theory suggests that this heterogeneity should reflect underlying characteristics of countries, i.e. factor endowments or productivity. However, recent developments in the international trade literature question this paradigm by showing that the current productive structure of a country is affected by its own past productive structure, through a path-dependent process governed by the relatedness between products (Hausmann and Klinger, 2007). Products are related because they share similar resources: knowledge bases, skills of the workforce, organizational arrangements, and supporting institutions (Essleztbichler, forthcoming). Countries can use these resources to diversify into new products: the more related the products, the easier it will be to leverage existing resources to develop a new product. The resulting diversification process is strongly

${ }^{(1)}$ The meaning and role of path dependence in economic geography, and more generally in social sciences, is currently a debated topic in the field (David, 2007; Henning et al., 2013; Martin and Sunley, 2006; Page, 2006). It is important to stress, however, that we share with the previous literature on relatedness and diversification the idea that path-dependence is not just the lock-in induced by small, random events in the past, but an evolutionary process in which economic and spatial outcomes emerge by the interaction between structures laid down in the past and the behavior of agents. 
path-dependent, in that the current set of diversification opportunities is constrained by the history of the diversification process itself. ${ }^{1}$

In this paper, we propose two contributions to the relatedness and diversification literature. First, we claim that the path-dependent process of product diversification is driven not only by each country past productive structure, but also by its relationships with other countries: countries are not isolated monads, but are embedded in several networks through different channels, such as geographical proximity, political relations, and international trade. These relationships affect the diversification into new products, by changing the structure of economic incentives, or by providing learning opportunities.

Second, we claim that the constraints of path-dependence are not equally binding for all countries. Capabilities may refer to very different domains: while some capabilities are important only for specific products or groups of products (e.g. specific technological knowledge), there are also capabilities that are relevant for all products, and are also country specific (e.g. institutions favoring or hindering entrepreneurship). Capabilities applying to many or all products provide a strong advantage for countries, by reducing the difficulty of diversifying into a new product and therefore also the role that product relatedness plays in this process. On the contrary, countries endowed mostly with capabilities specific to some products are more strongly constrained in their diversification process, because they are forced to rely exclusively on the links between products. Similar considerations apply also to learning: while some learning certainly occurs at the product level, absorptive capacity is an attribute that differs across firms (Cohen and Levinthal, 1990) and countries (Griffith et al., 2004; Mancusi, 2008). Countries with higher learning capabilities can exploit their network relations to gain the necessary knowledge to diversify into new products.

We will test these ideas by investigating the process of industrial diversification in the countries that were part of the European Union (EU-27) and those that were the target of the European Neighbourhood Policy (ENP) over the period 1995-2010. These countries provide an excellent setting for our analysis. First, it is possible to draw a clear-cut distinction between two groups of countries, with the EU group endowed with more general capabilities as an effect of the economic, political and institutional reforms induced by the accession process to the union. Second, the whole set of countries is also characterized by very close geographic, trade, and political relationships. ${ }^{2}$ To approximate the productive structure of countries, we will make use of world trade data that are derived from the BACI database (elaborated UN Comtrade data). Our results show that the evolution of the productive structure of countries - as proxied by their export mix — is strongly path-dependent: countries tend to keep a comparative advantage in products that are strongly related to their current productive structure, and they also diversify in related products. This effect is much stronger for ENP countries, signalling their lower capabilities to diversify in products that are not very related to their productive structure. We also show that the productive structures of countries are affected by their imports: countries keep a comparative advantage in products that are strongly related to their imports, but only EU countries (and not the ENP countries) show a strong capability to diversify in new products from related import sectors.

In the next section, we present the theoretical framework. Then we illustrate the methodology and the data. In the subsequent section, we present descriptive and econometric analyses. We conclude by discussing the policy and theoretical implications.

\section{The structure of the product space, diversification, and relatedness}

A striking characteristic of modern economies is the rich variety of the products they are able to provide. Some of the founding fathers of the economic science (Smith, 1776; Young,

(2) Moreover, ENP countries are also relevant from the policy perspective, as highlighted in the Introduction and other papers included in this Special Issue. 
1928) recognized that product heterogeneity matters, and that different products may have very different effects on the growth of countries. A more precise and formal account of these ideas has been provided by introducing the concept of product space (Hidalgo et al., 2007). The product space can be thought as a network representation of products-which are the nodes of the network-linked by their degree of relatedness, which is the extent to which they share similar resources and capabilities. By using international trade data to depict the product space, Hidalgo et al. (2007) showed that some products are in a dense part of the network - that is, they are related to many other products - whereas other products are in the periphery. This has important implications for economic performance: countries specialized in products located in the dense part of the product space have higher growth rates than countries specialized in more peripheral products.

Behind this result lies the idea of product relatedness as the commonality of resources and capabilities. If a country is specialized in a certain product, it clearly has the resources and capabilities to produce it. Resources and capabilities can be more easily redeployed to produce related products - that is products that require analogous capabilities. Therefore, countries specialized in products located in the dense part of the product space will have more opportunities to diversify into new products by redeploying their current capabilities and will have higher growth rates. Recent empirical evidence confirms the role played by capabilities in the diversification process. Industry case studies show that the most successful firms in new industries are founded by entrepreneurs with experience in related industries: many carriage-makers were able to redeploy their experience in the newly born automobile industry in the US (Klepper, 2002), and the dominant firms in the US radio industry also dominated the subsequent television receiver industry in the US (Klepper and Simons, 2000).

Although widely used in the literature, there is no consensus about the definition of resources and capabilities. At the firm level, resources are firm-specific assets (Teece et al., 1997) and capabilities identify complex routines or collection of routines that give an organization a set of options for producing specific outputs (Winter, 2003). Both are important sources of firms' competitive advantage because they cannot be easily imitated (Dosi et al., 2000). At the level of a geographical unit - a region (Lawson, 1999) or a country (Lall, 1992) - capabilities are not simply the aggregation of local firms capabilities ${ }^{3}$ : interdependencies and systemic elements need to be taken into account (von Tunzelmann, 2009a).

Finer distinctions between resources, services, competences and capabilities (von Tunzelmann, 2009b) play an important role for detailed analyses of the drivers of these elements in different contexts (Iammarino et al., 2008, 2012). However, for the sake of our argument, the key attributes are those providing competitive advantage: resources and capabilities must be valuable, rare, inimitable and non-substitutable (Barney, 1991). This applies as well to regional and country resources and capabilities that need to be localized and non-tradable to provide comparative advantage (Lawson, 1999; Neffke et al., 2014). Again, evidence of the role of capabilities emerges from works showing that relatedness is a fundamental driving force of diversification at the regional scale (i.e. the sub-national scale) in countries like Sweden (Neffke et al., 2011) and the US (Essleztbichler, forthcoming). Moreover, the related diversification process is stronger at the regional than the country level (Boschma et al., 2013), and this reinforces the idea of non-tradable and localized resources and capabilities.

Neffke et al. (2014) identify also another attribute of resources and capabilities, which is relevant in this context. Resources are specific to the economic activities they are used in: specialized suppliers or specialized labor pools are valuable for the sector in which the specialization occurs, but not necessarily for all other sectors. Capabilities are high-level

${ }^{(3)}$ In the same way that organizational capabilities are not simply the aggregation of the individual skills of its members (Nelson and Winter, 1982). 
routines or collection of routines, and therefore share the attributes of routines: they have specific patterns and objectives (Winter, 2003).

At a deeper look, however, the role and the extent of product specificity of resources and capabilities raise some issues. First of all, the concept of product space based on relatedness requires that resources and capabilities are not too specific, since they must be redeployed from a sector to another one. Second, specificity can be conceived as a matter of degree: there are some resources and capabilities that are very specific and can be redeployed only to a limited number of products and sectors, and there are some resources and capabilities that are less specific and can be applied to a variety of products and sectors. Third, it is also possible to conceive very general elements that apply virtually to all products and sectors within a geographical unit. These elements are similar to resources and capabilities in that they are localized and non-tradable - and therefore they provide comparative advantage. They can include both tangibles (e.g. infrastructure) and intangibles (e.g. institutions ${ }^{4}$ ), and for analogy we can label them as general resources and capabilities.

The existence of general resources and capabilities has important implications for the analysis of the diversification process based on relatedness. Countries well endowed with general resources and capabilities will be less constrained by specific resources and capabilities in the diversification process and will have more opportunities for unrelated diversification. On the contrary, countries where general resources and capabilities are weak or absent, the introduction of new industries is constrained within the limits of relatedness.

Consider the following example. There are two countries A and B, where only A is endowed with general resources and capabilities: for example, in country A markets for technologies (Arora et al., 2001) are well developed or the conditions for the creation of spinoffs (Klepper, 2007) are favorable. Let $\mathrm{F}$ be a biotechnology company specialized in cancer diseases. If the company discovers a new drug related to a different type of cancer, then it will be profitable to exploit it both in country A and in country B. However, if the new drug refers to a quite different domain (say, organ transplant rejection), it would be much easier to exploit it if $\mathrm{F}$ is located in country $\mathrm{A}$, where diversfication in unrelated industries is easier. In fact, even if $\mathrm{F}$ does not exploit the innovation directly, if in country A there are effective markets for technology or conditions enabling the creation of spinoffs other firms will exploit the innovation and we will observe that country A diversifies in the new product, whereas this would not happen in country B.

Summing up, our first claim is that the path-dependent process driving the diversification into new industries offers different degrees of freedom in different countries. In countries endowed with general resources and capabilities, we will observe a lower role of relatedness between products, whereas in countries where general resources and capabilities are lacking, we expect the opposite pattern.

A natural follow-up question is to ask whether there is any other condition that might reduce the strength of path-dependence in the diversification process. The productive structure of a country is affected by its own past history, but is also embedded in a network of relationships. It is certainly possible that these relationships can exert some influence on the direction and the intensity of the diversification process. Here we will consider in detail trade relationships. In the theoretical literature on international trade, it is not uncommon to find references to the possibility of learning from exports and imports (see e.g. Redding, 2010). At the empirical level, though, there is quite a lot of variation. Macro-level studies refer to the effects of trade on productivity and growth of countries (Singh, 2010) or regions (Boschma and Iammarino, 2009), and then they infer that some learning might explain the observed outcomes.

(4) Boschma and Capone (2015) explore in detail the role of institutions in the diversification process. 
More details on the mechanisms can be found in micro-level studies (Wagner, 2007, 2012). A well documented stylized fact is that firms engaging in exports have higher productivity: empirical evidence shows that this is at least partially due to self-selection of better firms into exporting behavior (Lileeva and Trefler, 2010). There is much less consensus on the existence of ex-post effects: some studies tend to suggest economies of scale explanations rather than learning (Silva et al., 2012), but there is also evidence of learning when using innovation measures (patents) rather than productivity (Alcacer and Oxley, 2014).

However, the situation is reverted in the case of imports: there is limited evidence for self-selection in importing activities, because of fixed costs (Altomonte and Békés, 2010), while much more convincing is the case for indirect forms of learning (Castellani et al., 2010). In fact, importing firms may exploit the availability of more variety in inputs and also the possibility that imported products embody higher quality. These processes are feasible even when absorptive capacity by firms is missing, because characteristics embedded in products do not require actual learning by firms. However, they might not be profitable in all countries: the availability of fitter and higher quality inputs can be exploited only when there is a demand (internal or foreign) that is sensitive to these issues. Otherwise, imports will have no impact on the probability of moving into new products. Imports might also operate on diversification through channels other than learning. Strong imports in a sector signal relevance of this sector for the productive structure of a country, and therefore provide a strong incentive for firms in the country to move into it. Still, if production was not occurring before, the required capabilities should be developed and this could be more difficult when suffering from strong international competition.

More generally, trade relationships might also signal other type of links between countries, such as mobility of workers or cultural similarities, that could also favor learning opportunities or provide pressure to remain active in sectors that were already well developed in the past. This is the reason why in our analysis we also control for geographical and cultural proximity.

The importance of geographical proximity is explained by the famous first law of geography: "everything is related to everything else, but near things are more related than distant things" (Tobler, 1970). More specifically, capabilities diffuse usually at quite a short range, because they are essentially based on tacit knowledge (Polanyi, 1962) that can be transmitted through mechanisms of social interactions, such as the mobility of workers (Almeida and Kogut, 1999; Breschi and Lissoni, 2009). Recent empirical evidence shows that distance matters also for the evolution of the productive structure of countries and their diversification paths (Bahar et al., 2012). Geographical proximity is also important as a control variable to examine trade relationships, since it is well known that trade is more intense at short distances (Leamer and Levinsohn, 1995), a finding which is confirmed for the EU-ENP countries (Petrakos et al., 2013).

We also consider the role that common culture can play, and in particular the existence of a colonial relationship between countries in the past. The colonial experience can have important and long-lasting effects on the economic performance of countries (Acemoglu et al., 2001). In our particular case, the presence of institutions developed by the colonizers or the diffusion of the language of the colonizing country might ease the transfer of tacit knowledge between two countries and therefore favor the diversification into products already present in the other country.

Summing up, our second claim is that the evolution of the productive structure of countries is affected by international trade relationships. In our analysis, we will focus specifically on imports, but we will also look at the impact of the productive structure of countries embedded in the trade network, that is of origin and destination countries. 


\section{Methodology and data}

In our empirical analysis, we use country-level world trade data from the BACI database for the period 1995-2010 (Gaulier and Zignago, 2010). This database is developed from UN Comtrade data using a procedure that reconciles the declarations of the exporter and the importer, allowing to extend considerably the number of countries with available trade data, including many countries in the European Neighbourhood Policy group. Moreover, data are available at a high level of product disaggregation (6-digit Harmonized System), although for the current analysis we use a 4-digit level, which includes 1,241 different products. ${ }^{5}$ Although international trade data do not match perfectly internal production activities, resources and capabilities, ${ }^{6}$ they provide a reasonable approximation of the industrial structure of countries, especially in cross-country comparisons: for this reason, they have been extensively used in past studies at the country (Hidalgo et al., 2007) and regional level (Boschma and Iammarino, 2009; Boschma et al., 2013). Moreover, relatedness indexes have been constructed in specific settings using different types of data, such as production at the firm level in the US (Bryce and Winter, 2009) and at the plant level in Sweden (Neffke et al., 2011), and yield results analogous to those obtained with trade data. We also use bilateral data about the distance between countries and the presence of colonial relationship from the CEPII GeoDist database (Mayer and Zignago, 2011). Descriptive statistics and correlations for all indicators described in this section and the variables used in the econometric analysis are reported in Appendix 1.

These data are used to build a set of indicators that capture the effects outlined in the theoretical section. Our first claim is that the effect of relatedness differs across countries: therefore, we need an indicator of relatedness. To this purpose, we follow closely the approach outlined by Hidalgo et al. (2007) and Hidalgo and Hausmann (2009). Boschma et al. (2012) showed that this relatedness measure performs better in the analysis of related variety and growth with respect to the alternative ex-ante (Frenken et al., 2007) and ex-post measures of related variety (Porter, 2003). Our starting point is the concept of comparative advantage developed by Balassa (1965). A country has a comparative advantage in a product $i$ when the share of this product in its exports is larger than the share of the product in the world exports.

The next step is the computation of a measure of proximity between products or industries. The proximity $(\varphi)$ between two products $(i$ and $j$ ) in a given year $t$ can be formally expressed as:

$$
\varphi_{i, j, t}=\min \left\{P\left(x_{i, t} \mid x_{j, t}\right), P\left(x_{j, t} \mid x_{i, t}\right)\right\}
$$

that is, the proximity between product $i$ and $j$ in year $t$ is the minimum between the conditional probability of having a comparative advantage in product $i$ given a comparative advantage in product $j$, and the conditional probability of having a comparative advantage in product $j$ given a comparative advantage in product $i$. The rationale behind the proximity measure is that if two products are related because they require similar institutions, infrastructure, productive inputs, organizational routines and capabilities, and technology, they are more likely to be produced together in the same country. Conditional probabilities rather than joint probabilities must be used, so that the measure is not affected by the relevance of the products in world trade. The minimum between conditional probabilities is used in order to ensure a symmetric and conservative measure.

Proximity is a property referring to the link between two products. In order to analyze countries, we need to place them in the product space. This can be done by using a density

\footnotetext{
${ }^{(5)}$ We use 4-digit rather than 6-digit data, because the computation of conditional probabilities is highly demanding for memory.

${ }^{(6)}$ This is due to the fact that many exports products require imported intermediate inputs. Moreover, trade data are also biased towards manufacturing.
} 
indicator that measures how close a product is to the current productive structure of a country. Formally, density can be expressed as follows:

$$
d_{i, c, t}=\sum_{j}\left(x_{j, c, t} \cdot \varphi_{i, j, t}\right) / \sum_{j} \varphi_{i, j, t}
$$

where $\varphi$ represents proximity (between product $i$ and product $j$ ), and $x$ takes the value of 1 if country $c$ has a comparative advantage in product $j$ at time $t$, and zero otherwise. So, density around product $i$ will be high if a country has a comparative advantage in most of the products related to the focal one. At the very extreme, it will be equal to 1 , if a country has a comparative advantage in all products with a non-zero proximity to the focal product. Conversely, density around product $i$ will be low (zero) if a country does not have a comparative advantage in most (any) of the products related to the focal one.

Our second theoretical claim refers instead to trade relationships. To capture the role of imports, we adapt the density indicator and develop an import density measure. The formal definition is analogous to the definition of density:

$$
i d_{i, c, t}=\sum_{j}\left(m_{j, c, t} \cdot \varphi_{i, j, t}\right) / \sum_{j} \varphi_{i, j, t}
$$

However, here $m$ takes the value of 1 if product $j$ has a higher share in the imports of country $c$ than in the world imports (we could say if country $c$ has a comparative "advantage" in importing product $j$ ), and zero otherwise. So, import density around product $i$ will be high if a country has a comparative "advantage" in importing most of the products related to the focal one. Conversely, import density around product $i$ will be low if a country does not have a comparative "advantage" in importing most of the products related to the focal one. In other words, this measure reflects the extent to which a country imports products that are related to the focal one-as related products should offer better learning opportunities to develop a comparative advantage.

Besides imports in a country, we also consider the productive structure of its trade partners. We employ two different strategies to select the relevant trade partners. First, we consider the most preferred countries in the trade relationships (Pinna, 2012). We use the comparative advantage of both the most preferred origin (the country with the highest share in the focal country-industry imports) and the most preferred destination (the country with the highest share in the focal country-industry exports).

Second, we specify a more detailed measure by considering all trade relationships. Rather than considering only one country, we use a weighted sum of the comparative advantage indicator of all the partner countries. The weight is given by the share of the partner country in the imports (exports) of the focal country-industry. Formally, the weighted comparative advantage indicator wca can be expressed as:

$$
w c a_{i, c, t}=\sum_{b}\left(M_{i, b, t}^{c} / M_{i, t}^{c}\right) \cdot x_{i, b, t}
$$

where $x_{i, b, t}$ is the comparative advantage indicator of country $b$ in product $i$ at time $t, M_{i, b, t}^{c}$ is the value of country $c$ imports of product $i$ from country $b$ at time $t$, and $M_{i, t}^{c}$ is the total value of country $c$ imports in product $i$. In the case of destinations, exports values are used instead of imports values. The weighted measure has a clear advantage with respect to the previous one (most preferred countries), because it is more detailed and it exploits all the available information, but it is also more difficult to provide an interpretation of its effects.

Since trade relationships are affected by geographical and institutional links, we include also some indicators referring to these factors as control variables in our analysis. We consider two forms of geographical proximity: sharing a border and simple distance between capital cities. In both cases, we use the comparative advantage of a proximate country. However, 
for each product category, we choose the country that has the highest comparative advantage ratio among the closest countries, that can be either all countries sharing a border, ${ }^{7}$ or the four nearest countries according to the mentioned distance. We use a similar indicator also for the colonial relationship. In this case, the comparative advantage is selected among all the countries that had a colonial link with the focal country.

\section{Results}

We start our analysis by describing the main patterns emerging from the data. First, we replicate in our sample the following stylized fact: countries have a higher probability to develop a comparative advantage in products characterized by higher density. Figure 1 presents the probability of developing a comparative advantage in a new product (five years later) for different density ranges in the EU (a) and ENP (b) case, respectively. In both cases, higher levels of density correspond to higher probabilities to develop a comparative advantage in new products. However, there are two important differences between the two groups. First, among the ENP countries, there are no products with density higher than 0.4, while from this level on, EU countries have the highest probability to develop a comparative advantage in new products. Second, for almost all levels of density, ENP countries have a higher probability to develop a comparative advantage in new products.

Interesting details emerge from a more disaggregated representation. In Figure 2, we plot average density in products with no comparative advantage against the number of new products where a comparative advantage has been developed five years later, for three different points in time (a: 1995; b: 2000; c: 2005). A positive relationship is evident in all cases. However, the plots also show a stronger relationship at lower average densities, and a higher variation over time in the number of new products for ENP countries. So, both Figure 1 and Figure 2 hint at the existence of a difference in the effect of density between EU and ENP countries.

What about import density? Remember that the density indicator measures the closeness of a good to the productive structure of a country. Density drives the evolution of countries productive structure, because it is easier for them to move to related products. The meaning and impact of import density are less clear-cut. A product with high import density is related to goods that are strongly needed in the country: this could be an important incentive for the country to produce it locally and could also provide an opportunity for learning from international trade. However, import density could also signal the lack of significant production capabilities: in this case, high import density would not be a driver for the evolution of the country productive structure, and it could even be associated to a lower probability of developing a comparative advantage in new products. Finally, a low import density might favor within-country production, because it could provide a space sheltered from international competition that could lead to the emergence of a strong national sector.

Analogous to what we have done for density, in Figure 3 we present the probability of developing a comparative advantage in a new product (five years later) for different import density ranges in the EU (a) and ENP (b) case, respectively. The results are quite striking. In the EU case, the probability of developing a comparative advantage in a new product increases strongly with import density. However, in the ENP case, the pattern is far less clear, and the highest probability peak is at very low levels of import density. This suggests that the mechanisms we have mentioned before might have different strengths in different groups of countries, which will be investigated below.

All the results presented so far are descriptive in nature. Therefore, we have to perform more formal tests to validate them.

${ }^{(7)}$ In this case, we exclude from the analysis the islands (Cyprus and Malta). 

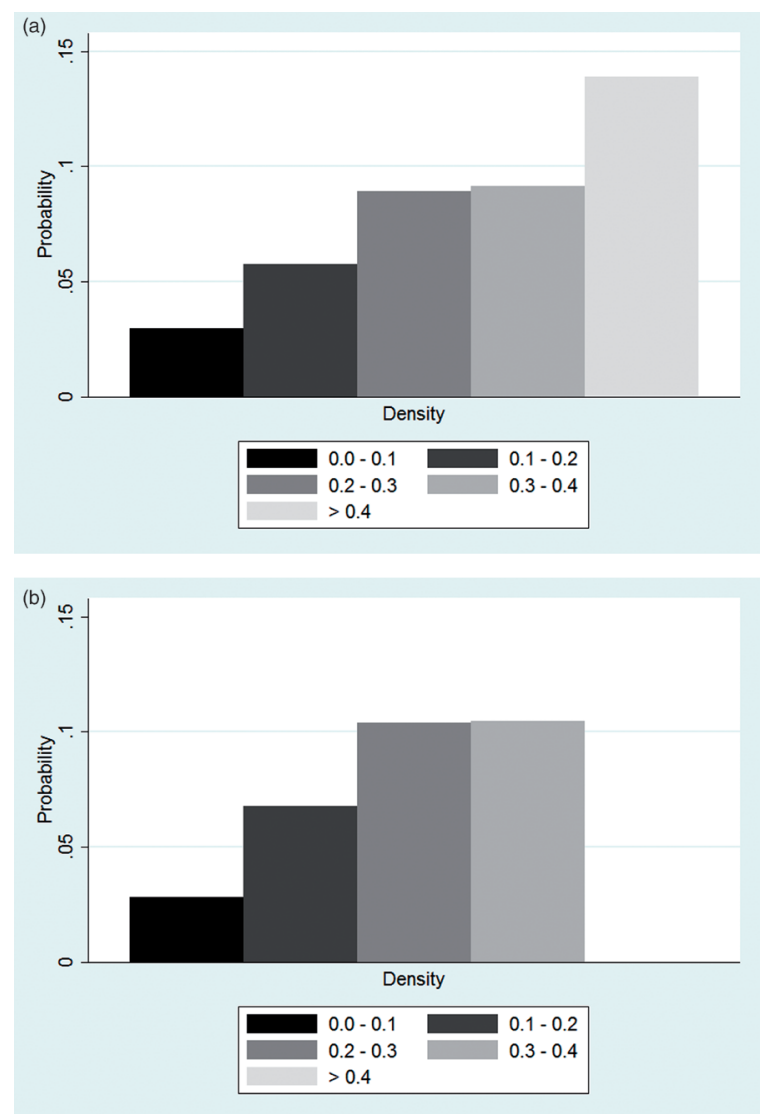

Figure 1. Probability of developing a comparative advantage in a new product (five years later) for different density ranges in the EU (a) and ENP (b) countries.
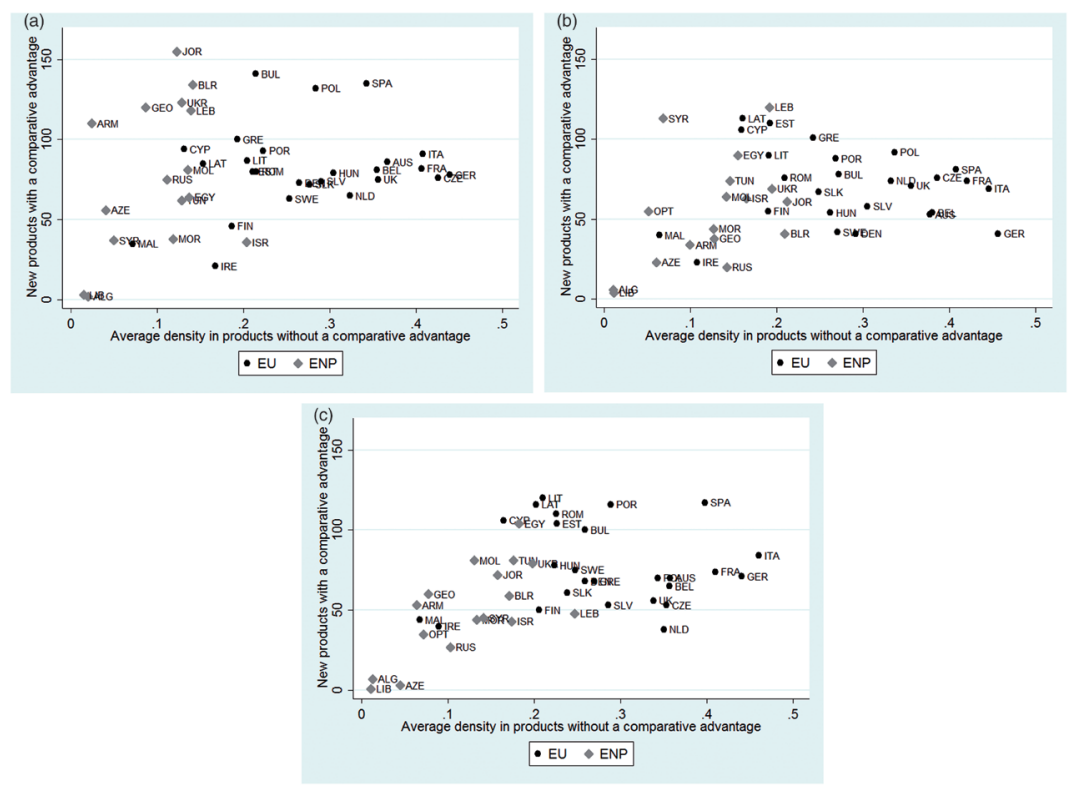

Figure 2. The relationship between density in products without a comparative advantage at time $t$ and new products with a comparative advantage at time $t+5$ in EU and ENP countries, with $t=1995$ (a), $t=2000$ (b), $t=2005$ (c). 

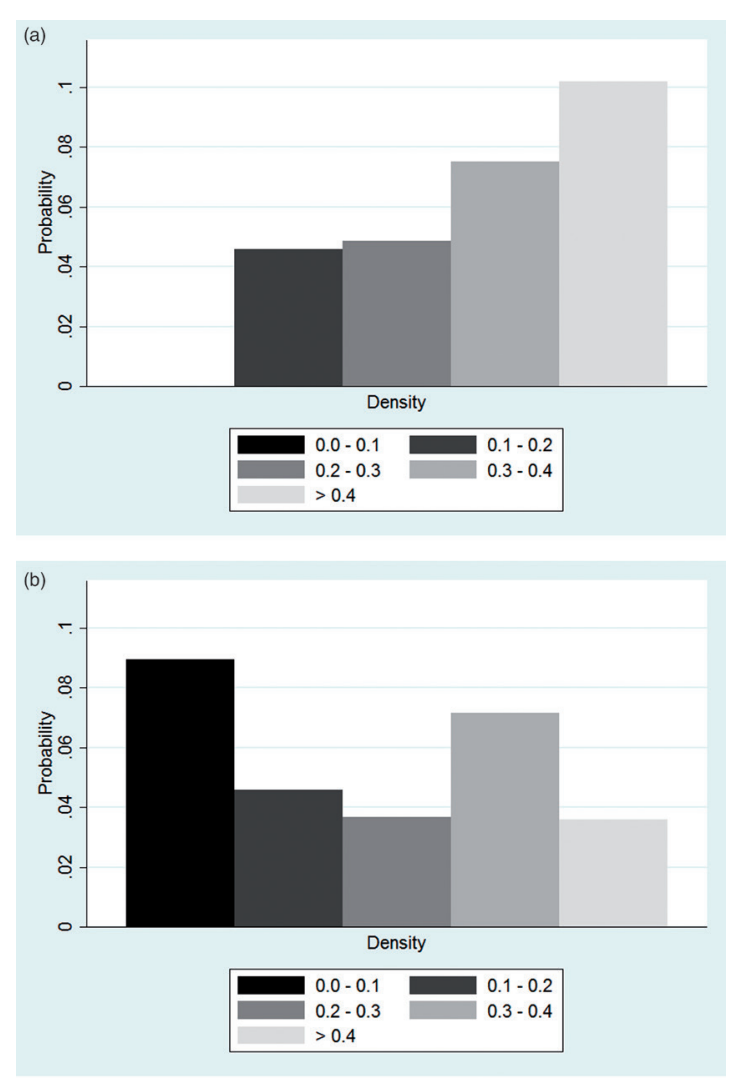

Figure 3. Probability of developing a comparative advantage in a new product (five years later) for different import density ranges in the EU (a) and ENP (b) countries.

Following Boschma et al. (2013) and Hausmann and Klinger (2007), we estimate the following equation:

$$
\begin{array}{r}
x_{i, c, t+5}=\alpha+\gamma \cdot x_{i, c, t}+\beta_{d}^{o} \cdot x_{i, c, t} \cdot d_{i, c, t}+\beta_{d}^{n} \cdot\left(1-x_{i, c, t}\right) \cdot d_{i, c, t}+\beta_{i d}^{o} \cdot x_{i, c, t} \cdot i d_{i, c, t}+ \\
+\beta_{i d}^{n} \cdot\left(1-x_{i, c, t}\right) \cdot i d_{i, c, t}+\delta_{d}^{o} \cdot x_{i, c, t} \cdot E N P \cdot d_{i, c, t}+\delta_{d}^{n} \cdot\left(1-x_{i, c, t}\right) \cdot E N P \cdot d_{i, c, t}+ \\
+\delta_{i d}^{o} \cdot x_{i, c, t} \cdot E N P \cdot i d_{i, c, t}+\delta_{i d}^{n} \cdot\left(1-x_{i, c, t}\right) \cdot E N P \cdot i d_{i, c, t}+\pi \cdot X+\varepsilon_{i, c, t}
\end{array}
$$

where the dependent variable takes value 1 if country $c$ has a comparative advantage in product $i$ at time $t+5$, and zero otherwise, $d_{i, c, t}$ denotes the density around product $i$ in country $c$ at time $t, i d_{i, c, t}$ denotes import density ${ }^{8}$ around product $i$ in country $c$ at time $t$, ENP is a dummy variable that takes value 1 if the country belongs to the European Neighbourhood Policy group, and zero if it belong to the European Union, and $X$ is a vector of country-year and product-year dummy variables, which control for any time-varying country or product characteristic. Both density and import density are normalized by subtracting the mean and dividing by the standard deviation.

Since we are interested in diversification, we distinguish between the effect of density and import density on keeping a comparative advantage in a product that is already part of the productive structure of a country and actual diversification, that is developing a comparative advantage in a product that was not part of the productive structure of a country: the coefficient $\beta_{d}^{O}\left(\beta_{i d}^{o}\right)$ captures the impact of density (import density) in keeping a comparative advantage

${ }^{(8)}$ Since import density is strongly correlated with density (because of the correlation between imports and exports) we include in the regression not the raw import density indicator, but the residuals of an ancillary regression of import density on density. 
in product $i$, and the coefficient $\beta_{d}^{n}\left(\beta_{i d}^{n}\right)$ captures the impact of density (import density) in developing a comparative advantage in a new product. The $\delta$ coefficients capture the existence of any difference in the impact of density and import density across EU and ENP countries. The model is estimated using OLS with country-clustered standard errors.

We include in the model the lagged dependent variable (with a 5 years lag $^{9}$ ), as the process exhibits strong persistence (Keele and Kelly, 2006). Including a lagged dependent variable in a fixed effects panel might result in severe bias (Arellano and Bond, 1991): this is due to the fact that fixed effects are computed over time periods, and therefore are correlated with time shocks in the error. This does not apply to our model: country-year fixed effects are computed over products, and product-year fixed effects are computed over countries. Therefore, they are not correlated with time shocks in the error. However, as a robustness check, we also estimate separate models for keeping a comparative advantage and developing a comparative advantage, in which the lagged dependent variable is not included. ${ }^{10}$

Results are presented in Table 1. Model 1 shows that both density and import density have a positive effect on both keeping a comparative advantage in a current product and developing a comparative advantage in a new product. However, consistently with previous findings in the literature, the former effect is stronger than the latter: both density and import density play a larger role in keeping a comparative advantage than in developing a new one. In model 2, we introduce the interaction effects: the results show that density has a stronger impact in the ENP countries, and this holds in the case of both current products and new ones. However, the impact of import density on keeping current comparative advantage is similar across the two groups of countries (the interaction effect is not significantly different from zero). Finally, while import density plays an important role in the development of a comparative advantage in new products in EU countries, it has no importance in the case of the ENP group, suggesting that the difference in the mechanisms behind import density refers specifically to the creation of a comparative advantage in new products (diversification) rather than to the retention of existing products. The robustness checks (Model 3 and 4) estimating the separate models qualitatively confirm these outcomes.

Results presented in Table 1 show that both our theoretical claims hold: the impact of relatedness as measured by density differs across different groups of countries (EU and ENP), and imports in a country also play a role. However, the relevance of trade relationships might not be captured only by our measure of import density: therefore, we refine our analysis by introducing in the model also indicators referring to the productive structure of trade partners. Whatever the measure we use, there are two reasons why the productive structure of trade partners might affect the evolution of the productive structure of a country. First, the presence of a comparative advantage signals the centrality of a product in the productive structure of a country: this provides the opportunity and the incentive for trade partners to keep active and even strengthen the trade relationships around the product. Second, a comparative advantage also signals the existence and the widespread diffusion of the capabilities required for a product: trade relationships with partners where these capabilities are strong enough might provide important learning opportunities.

The model we estimate is analogous to the one in equation (5), where we disentangle the effect of density and import density on keeping a comparative advantage in existing products and developing a comparative advantage in new products. To this model, we add the comparative advantage indicator of the most preferred origin and the most preferred

${ }^{(9)}$ All results are analogous adopting a three-year lag structure. As expected, reducing the lag the coefficient of the lagged variable increases in size, and the coefficients of all other explanatory variables decrease in size.

${ }^{(10)}$ Notice that in this case some bias can occur because country-year and product-year fixed effects are not estimated correctly. 
Table 1. Determinants of having a comparative advantage in the future.

\begin{tabular}{|c|c|c|c|c|}
\hline & (1) & $(2)$ & (3) & (4) \\
\hline Model & LPM & LPM & LPM & LPM \\
\hline D.V. & $\mathrm{CA}_{\mathrm{t}+5}$ & $\mathrm{CA}_{\mathrm{t}+5}$ & $\mathrm{CA}_{\mathrm{t}+5}$ & $\mathrm{CA}_{\mathrm{t}+5}$ \\
\hline \multirow[t]{2}{*}{$\mathrm{CA}_{\mathrm{t}}$} & $0.531^{* *}$ & $0.527^{* *}$ & & \\
\hline & $(0.0157)$ & $(0.0182)$ & & \\
\hline \multirow[t]{2}{*}{ Density on current } & $0.248^{* *}$ & $0.236^{* *}$ & $0.322^{* *}$ & \\
\hline & $(0.0152)$ & $(0.0144)$ & $(0.0286)$ & \\
\hline \multirow[t]{2}{*}{ Density on new } & $0.19^{* *}$ & $0.165^{* *}$ & & $0.163^{* *}$ \\
\hline & $(0.0132)$ & $(0.0114)$ & & $(0.0089)$ \\
\hline \multirow[t]{2}{*}{ Import density on current } & $0.044^{* *}$ & $0.056^{* *}$ & $0.08^{* *}$ & \\
\hline & $(0.0109)$ & $(0.01)$ & $(0.0119)$ & \\
\hline \multirow[t]{2}{*}{ Import density on new } & $0.021^{*}$ & $0.035^{* *}$ & & $0.029^{* *}$ \\
\hline & $(0.009)$ & $(0.0079)$ & & $(0.0058)$ \\
\hline \multirow[t]{2}{*}{ ENP $*$ density on current } & & $0.088^{*}$ & $0.214^{* *}$ & \\
\hline & & $(0.0379)$ & $(0.0602)$ & \\
\hline \multirow[t]{2}{*}{$\mathrm{ENP} *$ density on new } & & $0.083^{* *}$ & & $0.053^{* *}$ \\
\hline & & $(0.019)$ & & $(0.0188)$ \\
\hline \multirow[t]{2}{*}{ ENP * Imp. density on current } & & -0.029 & -0.011 & \\
\hline & & $(0.024)$ & $(0.0377)$ & \\
\hline \multirow[t]{2}{*}{ ENP * Imp. density on new } & & $-0.039^{* *}$ & & $-0.017^{*}$ \\
\hline & & $(0.0109)$ & & $(0.0085)$ \\
\hline Observations & 156,366 & 156,366 & 33,762 & 122,604 \\
\hline Adjusted $\mathrm{R}^{2}$ & 0.5214 & 0.5223 & 0.2577 & 0.0951 \\
\hline
\end{tabular}

Country-clustered standard errors in parentheses. All models include country-year and product-year dummy variables.

*** statistically significant at .01 and .05 , respectively.

destination and the corresponding ENP interactions (Model 1 of Table 2). In Model 4, instead, we use the weighted indicators described in the methodology section. As before, we also report results from models estimating separately the effect on keeping a comparative advantage and developing a comparative advantage (Model 2, 3, 5, 6).

The first result that can be extracted from Table 2 is that once we introduce the densities of trade partners the main effects and the ENP interaction effects are analogous to those emerging from the previous specification. This was not obvious, as they could capture effects similar to those already revealed by the import density of the focal country. Second, in both the most preferred country and the weighted specification, destination countries have a positive and significant effect on both the probability of keeping a comparative advantage and the probability of developing a comparative advantage in a new product. Third, the impact of origin countries is not stable across specifications: there is a positive and significant effect on keeping a product in the baseline models ( 1 and 4$)$, which does not hold in the separate models ( 2 and 5); moreover, in models 3 and 6 there is a positive and significant effect of 
Table 2. The effects of most preferred countries and weighted comparative advantage.

\begin{tabular}{|c|c|c|c|c|c|c|}
\hline & (1) & (2) & (3) & (4) & (5) & (6) \\
\hline Model & LPM & LPM & LPM & LPM & LPM & LPM \\
\hline \multirow[t]{2}{*}{ D.V. } & $\mathrm{CA}_{\mathrm{t}+5}$ & $\mathrm{CA}_{\mathrm{t}+5}$ & $\mathrm{CA}_{\mathrm{t}+5}$ & $\mathrm{CA}_{\mathrm{t}+5}$ & $\mathrm{CA}_{\mathrm{t}+5}$ & $\mathrm{CA}_{\mathrm{t}+5}$ \\
\hline & \multicolumn{3}{|c|}{ Most preferred countries } & \multicolumn{3}{|c|}{ Weighted trade links } \\
\hline \multirow[t]{2}{*}{$\overline{\mathrm{CA}_{\mathrm{t}}}$} & $0.493^{* *}$ & & & $0.465^{* *}$ & & \\
\hline & $(0.0178)$ & & & $(0.02)$ & & \\
\hline \multirow[t]{2}{*}{ Density on current } & $0.228^{* *}$ & $0.316^{* *}$ & & $0.225^{* *}$ & $0.312^{* *}$ & \\
\hline & $(0.0163)$ & $(0.0277)$ & & $(0.0167)$ & $(0.0273)$ & \\
\hline \multirow[t]{2}{*}{ Density on new } & $0.161^{* *}$ & & $0.157^{* *}$ & $0.159^{* *}$ & & $0.0153^{* *}$ \\
\hline & $(0.0118)$ & & $(0.0092)$ & $(0.0118)$ & & $(0.0092)$ \\
\hline \multirow[t]{2}{*}{ Import density on current } & $0.051^{* *}$ & $0.075^{* *}$ & & $0.046^{* *}$ & $0.071^{* *}$ & \\
\hline & $(0.0102)$ & $(0.0188)$ & & $(0.0105)$ & $(0.0188)$ & \\
\hline \multirow[t]{2}{*}{ Import density on new } & $0.031^{* *}$ & & $0.026^{* *}$ & $0.028^{* *}$ & & $0.023^{* *}$ \\
\hline & $(0.0078)$ & & $(0.0057)$ & $(0.0076)$ & & $(0.0056)$ \\
\hline $\mathrm{CA}_{\mathrm{t}}$ of destination & $0.04^{* *}$ & $0.028^{* *}$ & & $0.068^{* *}$ & $0.063^{* *}$ & \\
\hline on current & $(0.0074)$ & $(0.072)$ & & $(0.0134)$ & $(0.0155)$ & \\
\hline $\mathrm{CA}_{t}$ of destination & $0.018^{* *}$ & & $0.021^{* *}$ & $0.034^{* *}$ & & $0.038^{* *}$ \\
\hline on new & $(0.0029)$ & & $(0.0026)$ & $(0.0065)$ & & $(0.0059)$ \\
\hline $\mathrm{CA}_{t}$ of origin & $0.03^{*}$ & 0.004 & & $0.073^{* *}$ & 0.014 & \\
\hline on current & $(0.0129)$ & $(0.0092)$ & & $(0.0206)$ & $(0.0171)$ & \\
\hline $\mathrm{CA}_{t}$ of origin & -0.001 & & $0.008^{*}$ & -0.0002 & & $0.019^{* *}$ \\
\hline on new & $(0.0038)$ & & $(0.0031)$ & $(0.0058)$ & & $(0.005)$ \\
\hline \multirow[t]{2}{*}{ ENP $*$ density on current } & $0.089^{*}$ & $0.213^{* *}$ & & $0.09^{*}$ & $0.212^{* *}$ & \\
\hline & $(0.0382)$ & $(0.0601)$ & & $(0.0381)$ & $(0.0596)$ & \\
\hline \multirow[t]{2}{*}{ ENP * density on new } & $0.08^{* *}$ & & $0.053^{* *}$ & $0.084^{* *}$ & & $0.055^{* *}$ \\
\hline & $(0.0161)$ & & $(0.0186)$ & $(0.0168)$ & & $(0.0185)$ \\
\hline \multirow[t]{2}{*}{ ENP $*$ imp. density on current } & -0.025 & -0.006 & & -0.022 & -0.0002 & \\
\hline & $(0.0233)$ & $(0.0373)$ & & $(0.0233)$ & $(0.038)$ & \\
\hline \multirow[t]{2}{*}{ ENP $*$ imp. density on new } & $-0.035^{* *}$ & & $-0.015^{+}$ & $-0.031^{* *}$ & & -0.012 \\
\hline & $(0.011)$ & & $(0.0084)$ & $(0.011)$ & & $(0.0082)$ \\
\hline ENP $* \mathrm{CA}_{\mathrm{t}}$ of destination & -0.01 & -0.018 & & -0.026 & $-0.045^{+}$ & \\
\hline on current & $(0.0157)$ & $(0.0154)$ & & $(0.0246)$ & $(0.0265)$ & \\
\hline ENP $* \mathrm{CA}_{\mathrm{t}}$ of destination & $-0.01^{+}$ & & -0.007 & $-0.025^{* *}$ & & $-0.02^{*}$ \\
\hline on new & $(0.0053)$ & & $(0.0049)$ & $(0.0087)$ & & $(0.0081)$ \\
\hline $\mathrm{ENP} * \mathrm{CA}_{\mathrm{t}}$ of origin & 0.012 & 0.003 & & 0.009 & 0.004 & \\
\hline on current & $(0.023)$ & $(0.0165)$ & & $(0.0301)$ & $(0.0253)$ & \\
\hline $\mathrm{ENP} * \mathrm{CA}_{\mathrm{t}}$ of origin & 0.0001 & & 0.001 & -0.002 & & -0.003 \\
\hline on new & $(0.0058)$ & & $(0.004)$ & $(0.0086)$ & & $(0.0057)$ \\
\hline Observations & 156,366 & 33,762 & 122,604 & 156,366 & 33,762 & 122,604 \\
\hline Adjusted $\mathrm{R}^{2}$ & 0.5232 & 0.2583 & 0.0961 & 0.5235 & 0.2586 & 0.0965 \\
\hline
\end{tabular}

Country-clustered standard errors in parentheses. All models include country-year and product-year dummy variables.

${ }^{* * *}{ }^{*}+{ }^{+}$Statistically significant at $.01, .05$ and .10 percent, respectively. 
origin countries on diversification that was not present in the baseline models. Fourth, the effect of destination countries on diversification does not hold in the case of ENP countries. Taken together, these results strongly suggest that opportunities and incentives mechanisms are at work here: they are more powerful in keeping existing products than in developing new ones, and they are also less affected by the peculiar characteristics of the countries. However, some learning-by-exporting effect is also evident, although only in the case of more developed countries, signaling the importance of absorptive capabilities.

As it is well known, trade relations are affected by many variables, including geographical proximity, and cultural and historical relations. Therefore, our results on the role of import density and trade partners might be driven by these factors, and not by the trade relation in itself. So, to the previous mode ${ }^{11}$ we add the indicator of geographical and colonial links, and their interactions with the ENP dummy.

Results are presented in Table 3. For the geographical effects, we distinguish between contiguous countries (Models 1 to 3) and the nearest four countries (Models 4 to 6), as described in the methodology section. The main effects of both geographical and institutional control variables are positive and significant. In some specifications, the effect of colonial links differs across EU and ENP countries: with some precaution, we might say that only the former colonizers are able to exploit the colonial links, while for the colonies it does not provide any advantage for the evolution of the productive structure. The effects for all other explanatory variables are analogous to those obtained in the previous specifications.

\section{Conclusions}

In this article, we investigated the process of diversification in EU and ENP countries by using the proximity approach developed by Hausmann, Hidalgo and Klinger. Our results confirm the path-dependence in the diversification process: all analyzed countries tend to diversify into new industries that are related to their current productive structure, because they can exploit the existing capabilities. However, the effect of density is much stronger in the case of ENP countries, signaling the prominence of different types of resources and capabilities: EU countries are also able to diversify into less related industries because of more general resources and capabilities (such as infrastructure or institutions), while ENP countries have to rely much more on the relatedness between products and the specific resources and capabilities necessary to produce them.

Moreover, we also show that imports have an impact on the trajectory of the productive structure of countries, provided that absorptive capabilities exist. In our sample, only EU countries are able to diversify into sectors related to their imports. The productive structure of trade partners - in particular of destination countries - has a lower impact on the diversification process in countries: it provides economic incentives to both EU and ENP countries to keep producing in existing sectors that are related to what their partners do, and it also offer learning opportunities from the exports, at least in the case of EU countries.

We also show that geographical proximity matters in affecting the diversification process: countries have a higher probability to keep or develop a product if a neighbor already has a comparative advantage in it. A similar result holds in the case of colonial links. However, our main results hold even after controlling for these geographical and institutional variables that could affect trade relationships.

All results contribute to the literature on country diversification by showing that, although path dependence matters, there is still the possibility that the network of relations in which countries are embedded might change the direction and the intensity of diversification. Further research should look more specifically at the links between countries, by considering

${ }^{(11)}$ We only present results with the weighted indicator of trade partners. Results are analogous when using the other most preferred country indicator. 
Table 3. The role of geographic and institutional variables.

\begin{tabular}{|c|c|c|c|c|c|c|}
\hline & (1) & (2) & (3) & (4) & $(5)$ & (6) \\
\hline Model & LPM & LPM & LPM & LPM & LPM & LPM \\
\hline \multirow[t]{2}{*}{ D.V. } & $\mathrm{CA}_{\mathrm{t}+5}$ & $\mathrm{CA}_{\mathrm{t}+5}$ & $\mathrm{CA}_{\mathrm{t}+5}$ & $\mathrm{CA}_{\mathrm{t}+5}$ & $\mathrm{CA}_{\mathrm{t}+5}$ & $\mathrm{CA}_{\mathrm{t}+5}$ \\
\hline & \multicolumn{3}{|c|}{ Continuous neighbors } & \multicolumn{3}{|c|}{ Nearest four neighbors } \\
\hline \multirow[t]{2}{*}{$\mathrm{CA}_{\mathrm{t}}$} & $0.482^{* *}$ & & & $0.468^{* *}$ & & \\
\hline & $(0.0212)$ & & & $(0.0202)$ & & \\
\hline \multirow[t]{2}{*}{ Density on current } & $0.201^{* *}$ & $0.287^{* *}$ & & $0.213^{* *}$ & $0.291^{* *}$ & \\
\hline & $(0.0165)$ & $(0.0248)$ & & $(0.0156)$ & $(0.0238)$ & \\
\hline \multirow[t]{2}{*}{ Density on new } & $0.148^{* *}$ & & $0.145^{* *}$ & $0.147^{* *}$ & & $0.144^{* *}$ \\
\hline & $(0.0101)$ & & $(0.0092)$ & $(0.0106)$ & & $(0.0091)$ \\
\hline \multirow[t]{2}{*}{ Import density on current } & $0.038^{* *}$ & $0.071^{* *}$ & & $0.045^{* *}$ & $0.074^{* *}$ & \\
\hline & $(0.0106)$ & $(0.0177)$ & & $(0.0107)$ & $(0.0173)$ & \\
\hline \multirow[t]{2}{*}{ Import density on new } & $0.03^{* *}$ & & $0.022^{* *}$ & $0.027^{* *}$ & & $0.021^{* *}$ \\
\hline & $(0.0068)$ & & $(0.0059)$ & $(0.0073)$ & & $(0.0056)$ \\
\hline (Weighted) $\mathrm{CA}_{\mathrm{t}}$ & $0.058^{* *}$ & $0.05^{* *}$ & & $0.058^{* *}$ & $0.047^{* *}$ & \\
\hline of destination on current & $(0.0142)$ & $(0.0148)$ & & $(0.0128)$ & $(0.0144)$ & \\
\hline (Weighted) $\mathrm{CA}_{\mathrm{t}}$ & $0.029^{* *}$ & & $0.036^{* *}$ & $0.027^{* *}$ & & $0.034^{* *}$ \\
\hline of destination on new & $(0.0074)$ & & $(0.0067)$ & $(0.0065)$ & & $(0.0058)$ \\
\hline (Weighted) $\mathrm{CA}_{\mathrm{t}}$ & $0.077^{* *}$ & 0.002 & & $0.07^{* *}$ & 0.007 & \\
\hline of origin on current & $(0.0198)$ & $(0.0181)$ & & $(0.0208)$ & $(0.0178)$ & \\
\hline (Weighted) $\mathrm{CA}_{\mathrm{t}}$ & -0.007 & & $0.019^{* *}$ & -0.005 & & $0.017^{* *}$ \\
\hline of origin on new & $(0.007)$ & & $(0.0057)$ & $(0.006)$ & & $(0.005)$ \\
\hline \multirow[t]{2}{*}{ ENP $*$ density on current } & $0.103^{* *}$ & $0.222^{* *}$ & & $0.092^{*}$ & $0.222^{* *}$ & \\
\hline & $(0.0384)$ & $(0.0568)$ & & $(0.0375)$ & $(0.0599)$ & \\
\hline \multirow[t]{2}{*}{ ENP $*$ density on new } & $0.083^{* *}$ & & $0.053^{* *}$ & $0.087^{* *}$ & & $0.055^{* *}$ \\
\hline & $(0.0145)$ & & $(0.0178)$ & $(0.0159)$ & & $(0.0177)$ \\
\hline \multirow[t]{2}{*}{ ENP * imp. density on current } & -0.017 & -0.002 & & -0.024 & -0.008 & \\
\hline & $(0.0226)$ & $(0.037)$ & & $(0.0229)$ & $(0.0385)$ & \\
\hline \multirow[t]{2}{*}{ ENP $*$ imp. density on new } & $-0.036^{* *}$ & & $-0.015^{+}$ & $-0.032^{* *}$ & & -0.012 \\
\hline & $(0.01)$ & & $(0.0081)$ & $(0.0107)$ & & $(0.008)$ \\
\hline ENP $*$ (Weighted) $\mathrm{CA}_{\mathrm{t}}$ & -0.02 & -0.034 & & -0.02 & -0.036 & \\
\hline of destination on current & $(0.0259)$ & $(0.0277)$ & & $(0.025)$ & $(0.028)$ & \\
\hline ENP $*$ (Weighted) $\mathrm{CA}_{\mathrm{t}}$ & $-0.021^{*}$ & & $-0.019^{*}$ & $-0.021^{*}$ & & $-0.017^{*}$ \\
\hline of destination on new & $(0.0096)$ & & $(0.009)$ & $(0.0087)$ & & $(0.0082)$ \\
\hline ENP $*$ (Weighted) $\mathrm{CA}_{\mathrm{t}}$ & -0.005 & 0.009 & & 0.007 & 0.005 & \\
\hline of origin on current & $(0.0301)$ & $(0.026)$ & & $(0.0308)$ & $(0.0254)$ & \\
\hline ENP $*$ (Weighted) $\mathrm{CA}_{\mathrm{t}}$ & 0.003 & & -0.005 & -0.0004 & & -0.004 \\
\hline of origin on new & $(0.0092)$ & & $(0.006)$ & $(0.0087)$ & & $(0.0058)$ \\
\hline
\end{tabular}


Table 3. Continued

\begin{tabular}{lllllll}
\hline & $(1)$ & $(2)$ & $(3)$ & $(4)$ & $(5)$ & $(6)$ \\
$\mathrm{CA}_{\mathrm{t}}$ neighbor & $0.012^{*}$ & $0.027^{* *}$ & 0.002 & $0.013^{* *}$ & $0.023^{* *}$ & $0.007^{*}$ \\
& $(0.0049)$ & $(0.0091)$ & $(0.0052)$ & $(0.0033)$ & $(0.0079)$ & $(0.0037)$ \\
ENP * $\mathrm{CA}_{\mathrm{t}}$ neighbor & 0.012 & 0.021 & $0.014^{*}$ & 0.008 & 0.021 & 0.005 \\
& $(0.0076)$ & $(0.0248)$ & $(0.0069)$ & $(0.0061)$ & $(0.0196)$ & $(0.0058)$ \\
$\mathrm{CA}_{\mathrm{t}}$ colonial link & $0.017^{* *}$ & $0.02^{*}$ & $0.015^{* *}$ & $0.016^{* *}$ & $0.021^{*}$ & $0.012^{* *}$ \\
& $(0.0039)$ & $(0.0086)$ & $(0.0055)$ & $(0.0038)$ & $(0.0085)$ & $(0.0045)$ \\
$\mathrm{ENP}^{*} \mathrm{CA}_{\mathrm{t}}$ colonial link & $-0.016^{*}$ & -0.015 & $-0.015^{*}$ & $-0.014^{*}$ & -0.015 & -0.011 \\
& $(0.0067)$ & $(0.02)$ & $(0.0076)$ & $(0.0069)$ & $(0.0187)$ & $(0.007)$ \\
Observations & 145,197 & 32,121 & 113,076 & 152,643 & 32,952 & 119,691 \\
Adjusted $\mathrm{R}^{2}$ & 0.5341 & 0.2627 & 0.1021 & 0.5266 & 0.2632 & 0.0979 \\
\hline
\end{tabular}

Country-clustered standard errors in parentheses. All models include country-year and product-year dummy variables.

${ }^{* * *} .++$ statistically significant at $.01, .05$ and .10 percent, respectively.

more specific types of cultural relationships. Moreover, what is still missing in our analysis is a detailed account of why differences between countries in terms of general resources and capabilities exist and persist over time. Institutions like laws, customs, habits, and traditions might matter in this respect, as these have an impact on the incentives, frameworks, ideas, and behaviors of individuals and organizations. Some institutions directly favor or hinder the emergence of innovations (Lipsey, 2009; von Tunzelmann, 2003). There is actually a strong consensus on the role that institutions play in determining innovation and competitiveness of countries (see e.g. Cantwell, 2005; Lundvall, 1992; Menzel and Kammer, 2012) and regions (see e.g. Cooke et al., 1997; Crescenzi and Rodríguez-Pose, 2011; Storper, 1995). Therefore, we need to assess the impact of country- and region-specific institutions on the process of diversification (Boschma and Capone, 2015), and how that has affected the differences in the nature of diversification between EU countries (into less related industries) and ENP countries (into more related products). This can be done only partly by quantitative analyses using secondary data. Instead, qualitative comparative case studies are needed to gain insights into the role of (public, private, collective) agents and institutional change in the diversification process.

Drawing policy implications is a very delicate exercise with respect to the analysis conducted so far. The most striking characteristic emerging from the study of the product space and the diversification process of countries is the strong path-dependence: the productive structure of the past keeps exerting its influence many years later, and the position of countries in the product space is very stable over the whole period under analysis. Therefore, policy interventions should take into account that effects might display only over a long time period.

Our results show that in the case of ENP countries, product relatedness measured through density has a stronger effect both in keeping a comparative advantage in existing products and in diversifying into new products. Policy aimed at improving and speeding up the diversification process should consider that in these countries, this could be obtained mostly by favoring the development of related sectors. Directly favoring the creation of very distant industries might result in severe failures, since the lack of necessary supporting infrastructure and institutions may doom these initiatives before positive diffusion effects may occur. However, together with these interventions focused on nearby industries, policy makers might 
also consider actions aimed at improving the quality of the supporting institutions. Creating an environment where firms can emerge and grow more easily or returns from innovation can be better appropriated, might provide stronger incentives and opportunities for diversification even in very far products and therefore boost the future growth of countries.

Our findings on the role of imports and trade partners provide also important insights. While imports provide powerful incentives for both EU and ENP countries to keep producing in existing sectors where they already have comparative advantage, learning effects are circumscribed only to EU countries. In the ENP countries, the availability of a wider variety of inputs or of higher quality products does not produce positive effects, because of the lack of institutions, capabilities and probably demand. This is also the reason why colonial links are not effective in driving the diversification process. Therefore, policy aimed at improving institutions might be very useful also in this respect. Moreover, our result on geographical proximity suggests that the development of new accession countries that are closer to the ENP countries might have beneficial effects on the ENP policy, and that the links that exist because of physical proximity should be carefully exploited. However, more specific policies might also consider trade flows as a whole in these countries: sectors opening to international imports should also be opened very soon to opportunities in exports, so to have the possibility to grow and support the diversification process of countries.

Finally, our results on the role of trade partners do not support any role for general trade policies, at least in ENP countries. These countries do not benefit from the existing productive structures and capabilities of their trade partners: although trade openness might have beneficial effects on countries, our findings suggest that it would not improve diversification by itself.

Declaration of conflicting interests. The author(s) declared no potential conflicts of interest with respect to the research, authorship, and/or publication of this article.

Funding. The author(s) disclosed receipt of the following financial support for the research, authorship, and/or publication of this article: the Project "Sharing KnowledgE Assets: InteRregionally Cohesive NeigHborhoods" (SEARCH) within the 7th European Community Framework Program (FP7-SSH-2010.2.2-1), Grant Agreement 266834.

\section{References}

Acemoglu D, Robinson J A, Johnson S, 2001, "The colonial origins of comparative development: an empirical investigation" American Economic Review 91 1369-1401

Alcacer J, Oxley J, 2014, "Learning by supplying” Strategic Management Journal 35 204-223

Almeida P, Kogut B, 1999, "Localization of knowledge and the mobility of engineers in regional networks" Management Science 45 905-917

Altomonte C, Békés G, 2010, "Trade complexity and productivity”, CeFig working papers, 12, Center for Firms in the Global Economy

Arellano M, Bond S, 1991, "Some tests of specification for panel data: Monte Carlo evidence and an application to employment equations" Review of Economic Studies 58 277-297

Arora A, Fosfuri A, Gambardella A, 2001, "Markets for technology and their implications for corporate strategy" Industrial and Corporate Change 10 417-449

Bahar D, Hausmann R, Hidalgo CA, 2012, "International knowledge diffusion and the comparative advantage of nations", CID working paper, No. 235, Center for International Development, Harvard University, Cambridge, MA

Balassa B, 1965, "Trade liberalization and revealed comparative advantage" Manchester School of Economics and Social Studies 33 99-123

Barney J, 1991, "Firm resources and sustained competitive advantage" Journal of Management 17 99-120

Boschma R, Capone G, 2015, "Institutions and diversification: related versus unrelated diversification in a "varieties of capitalism" framework" Research Policy 44 1902-1914 
Boschma R, Iammarino S, 2009, "Related variety, trade linkages and regional growth" Economic Geography 85 289-311

Boschma R, Minondo A, Navarro M, 2012, "Related variety and regional growth in Spain" Papers in Regional Science 91 241-256

Boschma R, Minondo A, Navarro M, 2013, "The emergence of new industries at the regional level in Spain: a proximity approach based on product relatedness" Economic Geography 89 29-51

Breschi S, Lissoni F, 2009, "Mobility of skilled workers and co-invention networks: an anatomy of localized knowledge" Journal of Economic Geography 9 439-468

Bryce D J, Winter S G, 2009, “A general inter-industry relatedness index” Management Science 55 $1570-1585$

Cantwell J, 2005, "Innovation and competitiveness", in The Oxford Handbook of Innovation Eds J Fagerberg, D C Mowery, R R Nelson (Oxford University Press, Oxford) pp 243-267

Castellani D, Serti F, Tomasi C, 2010, 'Firms in international trade: importers' and exporters' heterogeneity in Italian manufacturing industry" The World Economy 33 424-457

Cohen W M, Levinthal D A, 1990, "Absorptive capacity: a new perspective on learning and innovation” Administrative Science Quarterly 35 128-152

Cooke P, Gomez Uranga M, Etxeberria G, 1997, "Regional innovation systems: institutional and organizational dimensions" Research Policy 26 475-491

Crescenzi R, Rodríguez-Pose A, 2011, Innovation and Regional Growth in the European Union (Springer, Berlin)

David P, 2007, "Path dependence: a foundational concept for historical social science" Cliometrica 1 91-114

Dosi G, Nelson R R, Winter S G (Eds), 2000, The Nature and Dynamics of Organizational Capabilities (Oxford University Press, Oxford)

Essleztbichler J, 2015, "Relatedness, industrial branching and technological cohesion in US metropolitan areas" Regional Studies 49 752-766

Frenken K, Van Oort F G, Verburg T, 2007, "Related variety, unrelated variety and regional economic growth" Regional Studies 41 685-697

Gaulier G, Zignago S, 2010, "BACI: international trade database at the product level", The 1994-2007 version, CEPII working paper, No. 2010-23, Centre d'Etudes Prospectives et d'Informations Internationales, Paris

Griffith R, Redding S J, van Reenen J M, 2004, "Mapping the two faces of R\&D: productivity growth in a panel of OECD industries" Review of Economics and Statistics 86 883-895

Hausmann R, Klinger B, 2007, "The structure of the product space and the evolution of comparative advantage", CID working paper, No. 146, Center for International Development, Harvard University, Cambridge, MA

Henning M, Stam E, Wenting R, 2013, Path dependence research in regional economic development: cacophony or knowledge accumulation?" Regional Studies 47 1348-1362

Hidalgo C A, Hausmann R, 2009, "The building blocks of economic complexity" Proceedings of the National Academy of Sciences 106 10570-10575

Hidalgo C A, Klinger B, Barabàsi A L, Hausmann R, 2007, "The product space conditions the development of nations" Science $317482-487$

Iammarino S, Padilla-Pérez R, von Tunzelmann N, 2008, “Technological capabilities, and global-local interactions: the electronics industry in two Mexican regions" World Development 36 1980-2003

Iammarino S, Piva M, Vivarelli M, von Tunzelmann N, 2012, "Technological capabilities and patterns of innovative cooperation of firms in the UK regions" Regional Studies 46 1283-1301

Keele L, Kelly NJ, 2006, "Dynamic models for dynamic theories: the ins and outs of lagged dependent variables" Political Analysis 14 186-205

Klepper S, 2002, "The capabilities of new firms and the evolution of the US automobile industry" Industrial and Corporate Change 11 645-666

Klepper S, 2007, "Disagreements, spinoffs, and the evolution of Detroit as the capital of the U.S automobile industry" Management Science 53 616-631

Klepper S, Simons K L, 2000, "Dominance by birthright: entry of prior radio producers and competitive ramifications in the U.S. television receiver industry" Strategic Management Journal 21 997-1016 
Lall S, 1992, "Technological capabilities and industrialization" World Development 20 165-186

Lawson C, 1999, "Towards a competence theory of the region" Cambridge Journal of Economics 23 $151-166$

Leamer E E, Levinsohn J, 1995, "International trade theory: the evidence", in Handbook of International Economics Vol 3 Eds G Grossman, K S Rogoff (Elsevier, Amsterdam) pp 1339-1394

Lileeva A, Trefler D, 2010, "Improved access to foreign markets raises plant-level productivity for some plants" The Quarterly Journal of Economics 125 1051-1099

Lipsey R G, 2009, "Economic growth related to mutually interdependent institutions and technology" Journal of Institutional Economics 5 259-288

Lundvall B A, 1992, National Systems of Innovation: Towards a theory of Innovation and Interactive Learning (Pinter, London)

Mancusi M L, 2008, "International spillovers and absorptive capacity: a cross-country cross-sector analysis based on patents and citations" Journal of International Economics 76 155-165

Martin R, Sunley P, 2006, "Path dependence and regional economic evolution" Journal of Economic Geography 6(4) 395-437

Mayer T, Zignago S, 2011, "Notes on CEPII's distances measures: the GeoDist Database", CEPII working paper, No. 2011-25, Centre d'Etudes Prospectives et d'Informations Internationales, Paris

Menzel M P, Kammer J, 2012, "Industry evolution in varieties-of-capitalism: a survival analysis on wind turbine producers in Denmark and the USA", Papers in evolutionary economic geography, No. 12.20, Utrecht University, Utrecht

Neffke F, Hartog M, Boschma R, Henning M, 2014, "Agents of structural change. The role of firms and entrepreneurs in regional diversification", Papers in evolutionary economic geography, No. 14.10, Utrecht University, Utrecht

Neffke F, Henning M, Boschma R, 2011, "How do regions diversify over time? Industry relatedness and the development of new growth paths in regions" Economic Geography 87 237-265

Nelson R R, Winter S G, 1982, An Evolutionary Theory of Economic Change (Harvard University Press, Cambridge, MA)

Page S E, 2006, "Path dependence" Quarterly Journal of Political Science 1 87-115

Petrakos G, Kallioras D, Anagnostou A, 2013, "The geography of trade relations between the EU and the ENP countries: emerging patterns and determinants" SEARCH working paper, 2/08

Pinna A, 2012, "Is the EU the best trade partner for its neighbors?" SEARCH working paper, 2/02

Polanyi M, 1962, Personal Knowledge: Towards a Post-Critical Philosophy (Routledge, London)

Porter M, 2003, "The economic performance of regions" Regional Studies 37 549-578

Redding S J, 2010, "Theories of heterogeneous firms and trade" NBER working paper, 16562, National Bureau of Economic Research, Cambridge, MA

Silva A, Afonso O, Africano AP, 2012, "Learning-by-exporting: what we know and what we would like to know" The International Trade Journal 26 255-288

Singh T, 2010, "Does international trade cause economic growth? A survey" The World Economy 33 $1517-1564$

Smith A, 1776, An Inquiry into the Nature and Causes of the Wealth of Nations (Strahan and Cadell, London)

Storper M, 1995, "The resurgence of regional economies, ten years later: the region as a nexus of untraded interdependencies" European Urban and Regional Studies 2 191-221

Teece D J, Pisano G, Shuen A, 1997, "Dynamic capabilities and strategic management" Strategic Management Journal 18 509-533

Tobler W R, 1970, “A computer movie simulating urban growth in the Detroit region” Economic Geography 46 234-240

von Tunzelmann N, 2003, "Historical coevolution of governance and technology in the industrial revolutions" Structural Change and Economic Dynamics 14 365-384

von Tunzelmann N, 2009a, "Regional capabilities and industrial regeneration", in Technological Change and Mature Industrial Regions: Firms, Knowledge and Policy Eds M Farshchi, O Janne, P McCann (Edward Elgar, Aldershot) pp 11-28

von Tunzelmann N, 2009b, "Competence versus capabilities: a reassessment" Economia Politica 26 $435-464$ 
Wagner J, 2007, "Exports and productivity: a survey of the evidence from firm-level data" The World Economy 30 60-82

Wagner J, 2012, "International trade and firm performance: a survey of empirical studies since 2006" Review of World Economics 148 235-267

Winter SG, 2003, "Understanding dynamic capabilities" Strategic Management Journal 24 991-995

Young A, 1928, "Increasing returns and economic progress" The Economic Journal 38 527-542 


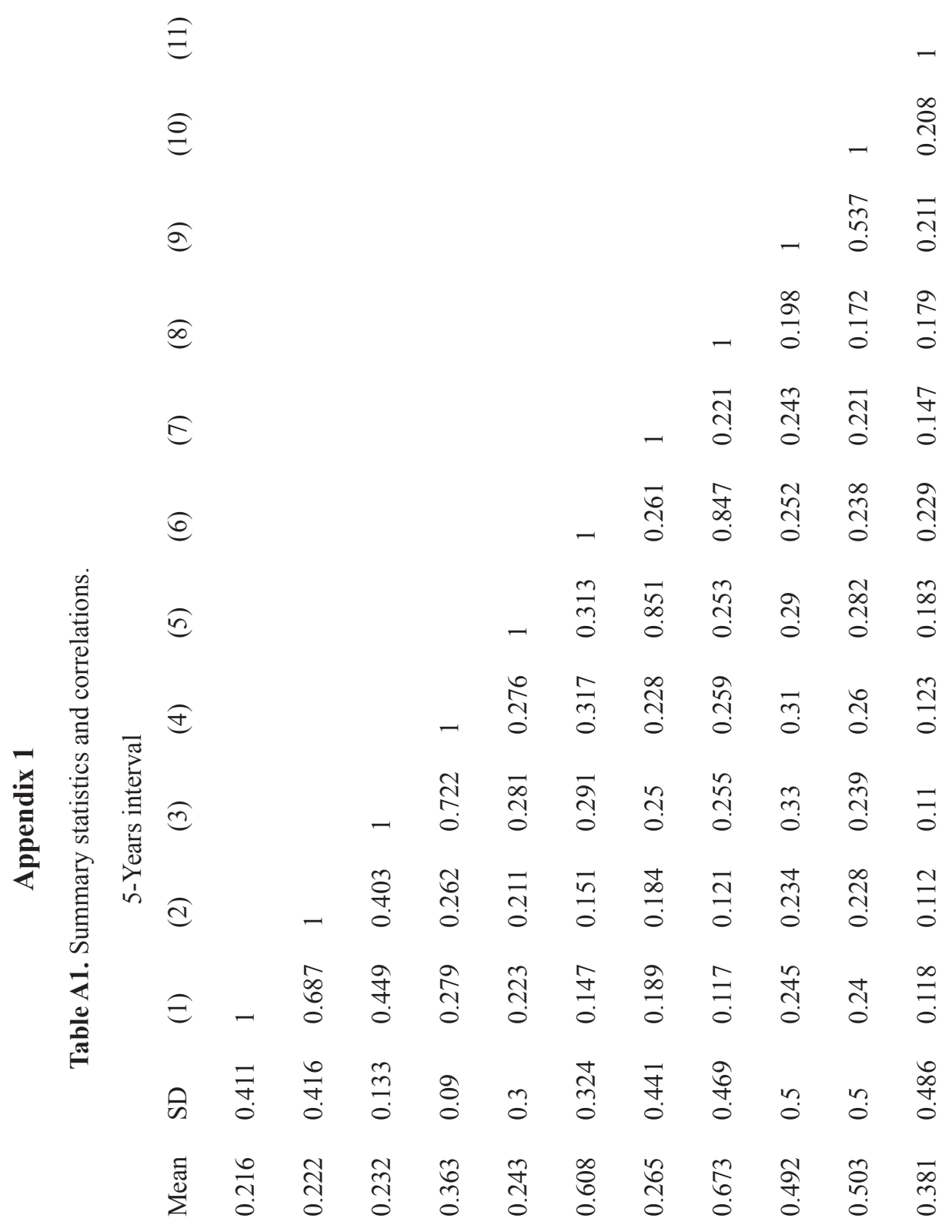

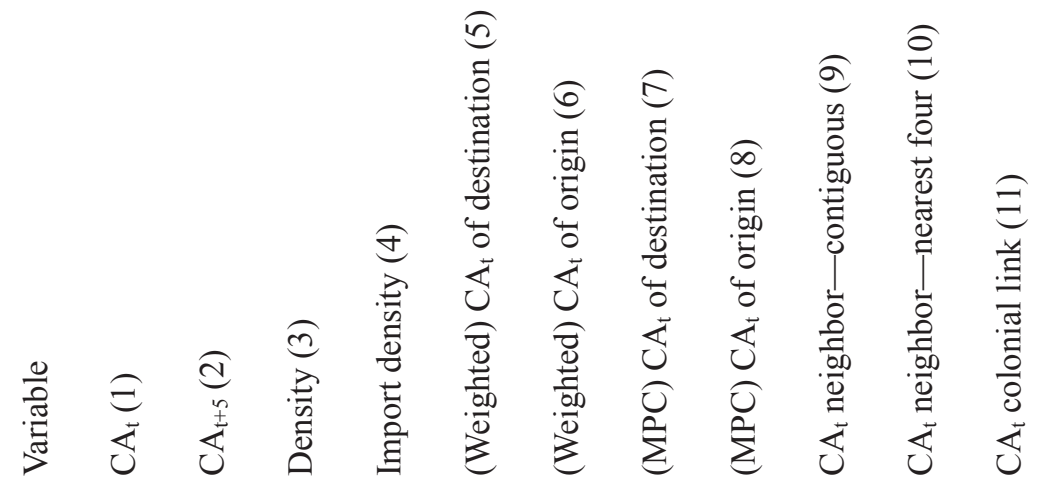

